Review Article

\title{
The Keap1-Nrf2 system and diabetes mellitus
}

Akira Uruno $^{\mathrm{a}, \mathrm{b}, 1, *}$, Yoko Yagishita ${ }^{\mathrm{a}, 1}$, Masayuki Yamamoto ${ }^{\mathrm{a}, *}$

${ }^{a}$ Department of Medical Biochemistry, Tohoku University Graduate School of Medicine, 2-1 Seiryo-machi, Aoba-ku, Sendai 980-8575, Japan

${ }^{\mathrm{b}}$ Bioscience for Drug Discovery, Tohoku University Graduate School of Medicine, 2-1 Seiryo-machi, Aoba-ku, Sendai 980-8575, Japan

*Corresponding author; Fax: +81 227178090

E-mail address: masiyamamoto@med.tohoku.ac.jp (M. Yamamoto) and uruno@med.tohoku.ac.jp (A. Uruno)

${ }^{1}$ These authors have equally contributed to this manuscript.

Abbreviations used:

8-OHdG, 8-hydroxy-2'-deoxyguanosine; AMPK, AMP-activated protein kinase; ARE, antioxidant response element; ChIP-Seq, chromatin immunoprecipitation sequencing; CNC, Cap-n-collar; DIO, diet-induced obesity; EpRE, electrophile response element; Keap1, Kelch-like ECH-associated protein 1; Neh, NRF2-ECH homology; NF-E2, nuclear factor erythroid 2; Nrf1, NF-E2-related factor 1; Nrf2, NF-E2-related factor 2; Nrf3, NF-E2-related factor 3; RNS, reactive nitrogen species ROS, reactive oxygen species; SOD, superoxide dismutase; STZ, streptozotocin 


\begin{abstract}
Nrf2 (NF-E2-related factor 2) plays a key role in the protection of vertebrates against environmental stress by contributing to the inducible expression of detoxification and antioxidant enzymes. Keap1 (Kelch-like ECH-associated protein 1) is a sensor for oxidative and electrophilic stresses. Keap1 also acts as an E3 ubiquitin ligase substrate-recognition subunit that specifically targets Nrf2. Keap1 causes Nrf2 to be degraded through the ubiquitin-proteasome pathway and thus ensures that Nrf2 is constitutively suppressed under unstressed conditions. Upon exposure to oxidative or electrophilic stress, Keap1 loses its ability to ubiquitinate Nrf2. Many lines of evidence have recently clarified that the Keap1-Nrf2 system also plays critical roles in the maintenance of cellular homeostasis. One of the most salient examples is the contribution of Keap1-Nrf2 to metabolic and energy-balance regulation. In particular, how the Keap1-Nrf2 system protects the body against diabetes mellitus and how perturbations in this system provoke the disease condition are now under intense investigation. This review will summarize the recent progress made in this area.
\end{abstract}




\section{Introduction}

Nrf2 (NF-E2-related factor 2) belongs to a small family of transcription factors harboring a unique basic-leucine-zipper motif, the CNC (cap-n-collar) family $[1,2]$. Nrf2 induces a set of antioxidant and detoxification enzyme genes and plays critical roles in the protection of the body against various environmental stresses, such as electrophiles, reactive oxygen species (ROS) and reactive nitrogen species (RNS) [3, 4]. Keap1 (Kelch-like ECH-associated protein 1) is a component of the Cullin3-based ubiquitin E3 ligase that plays a substrate adaptor function [5]. Keap1 subjects Nrf2 to rapid ubiquitination and degradation and thus suppresses the transcriptional activity of Nrf2 under unstressed conditions. When cells are exposed to oxidative or electrophilic stress, the cysteine residues of Keap1 are modified, and Keap1 loses its ability to ubiquitinate Nrf2; in this way, Nrf2 accumulates within the cell and induces the expression of its target genes. This regulatory system has been referred to as the Keap1-Nrf2 system, which plays a central role in protecting cells from environmental stress.

Diabetes mellitus is a common metabolic disorder with severe complications. The population suffering from diabetes mellitus and its complications has been increasing [6]. It has been noted that oxidative stress conditions in the body are correlated with impairment of blood glucose regulation. In particular, the findings that pancreatic islets poorly express antioxidant enzymes [7] and retain low-level antioxidant activity [8] suggest to us that oxidative stress in pancreatic islets plays an important role in the pathogenesis and/or progression of diabetes mellitus. Indeed, hyperglycemia-mediated oxidative stress appears to be involved in various diabetic complications in animal 
models of diabetes [9-12], and oxidative stress is actually increased in diabetes patients [13]. Thus, the roles played by the Keap1-Nrf2 system in the pathogenesis of diabetes mellitus and in the development of its complications have emerged as important research topics.

In this respect, it should be noted that the Keap1-Nrf2 system has been found to exert various biological functions other than protection against the environmental stress response. Importantly, there are accumulating lines of evidence indicate that Nrf2 directly regulates genes related to cellular metabolism $[14,15]$; metabolic regulation and reprogramming of this regulation upon malignant transformation seem to be two of the major contributions of the Keap1-Nrf2 system.

\section{Cloning of Nrf2 and Keap1}

Nrf2 was cloned by homology to an erythroid-specific transcription factor p45 NF-E2 (nuclear factor erythroid 2) for a $\beta$-globin gene regulator in erythroid cells [1] and subsequently shown to form a heterodimer with one of the small Maf (sMaf) transcription factors $[1,16]$. There are three sMaf proteins, MafF, MafG and MafK, within mammalian cells, and these three factors show high levels of structural similarity and redundant functions [17-19]. The binding site sequence of p45-sMaf (NF-E2 box; TGCTGA(G/C)TCA(T/C)) shares a high similarity with those of the cis-regulatory elements identified in the regulatory regions of detoxification and antioxidant enzyme genes, i.e., ARE/EpREs (antioxidant/electrophile response elements; TGCnnn(G/C)TCA(T/C)) [20, 21]. Based on this cis-element sequence similarity, we surmised that one of the CNC-sMaf transcription factor dimers activates the 
transcription of detoxification and antioxidant enzyme genes through ARE/EpREs [3, 4].

Because Nrf2 is expressed abundantly in lung, intestine and esophagus, we examined the functional contributions of the Nrf2-sMaf heterodimer utilizing the mouse Nrf2 gene knockout line [3]. The results revealed that the expression of detoxifying and antioxidant enzyme genes is simultaneously abrogated in Nrf2 knockout mice, demonstrating the critical role Nrf2 plays in the protection against xenobiotic/electrophilic metabolites and oxidative stress-induced damage.

To clarify how Nrf2 is regulated during this cytoprotection process, structure-function analyses of six functional Nrf2 domains were conducted. These domains were first determined by the structural similarity between the chicken Nrf2 $(\mathrm{ECH})$ protein and the human Nrf2 protein, such that the domains are referred to as Neh (Human NRF2-chicken ECH homology) domains (Fig. 1a) [5]. Of the Neh domains, an especially intriguing domain is Neh2, as this domain appears to act as a degron for Nrf2. We therefore carried out a yeast two-hybrid screen to identify proteins that interact with the Neh2 domain of Nrf2 and thereby discovered Keap1 [5]. Keap1 acts as a substrate-recognizing adaptor component for Cul3-based ubiquitin ligase and ubiquitinates the Neh2 domain of Nrf2. Keap1 also acts as a sensor for various environmental stresses.

\section{Cytoprotective functions of Nrf2}

In detoxifying reactions, xenobiotics are first metabolized in phase I reactions involving cytochrome P450. The metabolites are usually electrophilic and highly 
cytotoxic, but they are subsequently processed by phase II enzymes and modified by sulfation, acetylation, glucuronidation or glutathione conjugation to acquire hydrophilicity. Nrf2 strongly induces the expression of phase II detoxification enzyme

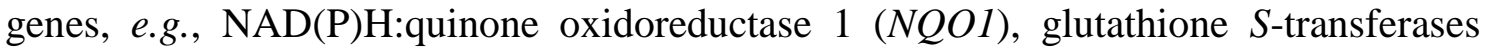
$(G S T s)$ and UDP glucuronosyltransferases $(U G T S)$ [3, 22, 23]. Nrf2 also enhances the expression of glutathione synthesis and $\mathrm{ABC}$ transporter-related genes that excrete metabolites, including the genes encoding the cystine/glutamate exchange transporter (SLC7A11 or System $\mathrm{Xc}^{-}$), both subunits of $\gamma$-glutamylcysteine synthetase $(G C L)$ and multi-drug resistance-associated protein 1 (MRPs) [4, 22, 24, 25]. In addition to these xenobiotic metabolism-related enzyme genes, Nrf2 also induces antioxidant genes, such as heme oxygenase-1 (HO-1 or HMOX1), peroxiredoxin 1 (PRDXI), glutathione peroxidase $2(G P X 2)$, thioredoxin reductase 1 (TXNRD1) and sulfiredoxin $(S R X)$ [4, 26-30]. As Nrf2-knockout mice are fragile to xenobiotics and oxidative stress [22, 31], these observations strongly support the contention that Nrf2 coordinately protects cells against environmental stresses.

\section{Molecular basis of Keap1-Nrf2 function}

As shown in Figure 1a, Nrf2 has six functional domains, which were first defined by the sequence similarity between human NRF2 and chicken ECH1; these domains are referred to as Neh (NR2-ECH homology) domains [5]. Of the Neh domains, the Neh2 domain acts as a degron and is involved in the Keap1-dependent degradation of Nrf2 [5]. The Neh4 and Neh5 domains were found to interact with CREB-binding protein $(\mathrm{CBP})$ and other transcriptional co-activators and to contribute to the 
transcriptional activation of target genes [32]. The Neh6 domain acts as a Keap1-independent degron that interacts with $\beta$-transducin repeat-containing protein $(\beta-\operatorname{TrCP})[33,34]$. The Neh1 domain corresponds to a basic-region and leucine zipper domain that facilitates the binding of Nrf2 to DNA [5].

The cellular content of Nrf2 is usually very low, as Keap1 negatively regulates Nrf2 through ubiquitination and proteasomal degradation. Nrf2 directly interacts with Keap1 through two motifs in the Neh2 domain, i.e., high affinity ETGE and low affinity DLG motifs $[35,36]$. Under unstressed conditions, seven ubiquitination target lysine residues (7Ks) between the ETGE and DLG motifs are ubiquitinated by the Keap1-containing E3 ubiquitin ligase and subsequently degraded through the proteasome pathway.

Recent analyses of Nrf2 somatic mutations in human cancer revealed that the extended sequence of the DLG motif is involved in the interaction with Keap1 [37]. An amino acid motif corresponding to Met17-Gln51 (DLGex) also appears to contribute to the interaction with the Keap1 DC domain, though this region is much wider than that of the ETGE motif [37]. Structural analysis demonstrated that while the ETGE motif consists of a simple $\beta$ hairpin conformation and enables electrostatic interactions with the Keap1 DC domain, the DLGex motif is composed of a complicated and fragile triple helix structure that interacts weakly with the Keap1 DC domain. Because the binding affinity between the DLGex motif and the DC domain is much weaker than that of the ETGE motif with the DC domain [35, 37, 38], it is hypothesized that some electrophilic stresses dissociate the weaker interaction between the DLGex motif and the DC domain [39]. This mechanism is called a hinge and latch model (Fig. 1b). As 
a result of the dissociation between the Keap1 and Nrf2 molecules, Nrf2 escapes from proteasomal degradation and accumulates in the nucleus [40].

\section{Multiple cysteine residues in Keap1 sense distinct stresses}

Molecular dissection of Keap1 revealed the presence of five domains (Fig. 1c). Of these domains, the N-terminal BTB ( Broad complex, Tramtrack and Bric-a-brac) domain, the IVR (Intervening Region) and the C-terminal DC domain containing a

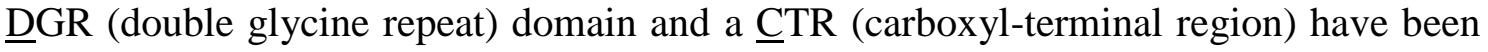
well characterized [5]. The BTB domain is involved in the homodimerization of Keap1, while the DC domain contributes to the binding of Keap1 to Nrf2.

Keap1 contains multiple cysteine residues that serve as unique sensor systems for various environmental stresses, including electrophiles, ROS, RNS and heavy metals [41]. Important cysteine residues for sensing electrophiles have been identified in the BTB domain (Cys151) and IVR (Cys273/288).

Mutation of Cys151 to serine (C151S) abrogates the Nrf2 induction mediated by electrophiles, including diethyl maleate (DEM), tert-butylhydroquinone (tBHQ), sulforaphane and dimethylfumarate (DMF), in murine peritoneal macrophages and embryonic fibroblasts, demonstrating that Cys151 is the major cysteine residue responsible for Nrf2 induction [42]. In contrast, the Keap1 C151S mutant does not lose the Nrf2 induction mediated by 15 -deoxy- $\Delta^{12,14}$-prostaglandin $\mathbf{J}_{2}\left(15 \mathrm{~d}-\mathrm{PGJ}_{2}\right)$, ebselen, cadmium chloride, nitro oleic acid or CDDO-Im (oleanolic triterpenoid 1-[2-cyano-3,12-dioxooleane-1,9(11)-dien-28-oyl] imidazole), indicating that these chemicals utilize other cysteine residues [42]. 
Cys273/288 have been shown to contribute to $15 \mathrm{~d}-\mathrm{PGJ}_{2}$-mediated Nrf2 induction [43]. When cells are exposed to nitric oxide (NO), a second messenger molecule, 8-nitro-cGMP, is generated. This 8-nitro-cGMP has been found to $S$-guanylate Cys434 of Keap1 [44]. These results indicate that multiple cysteine residues contribute to the multiple sensor functions of Keap1.

\section{The Keap1-Nrf2 system in blood glucose homeostasis}

Insulin is a key hormone for maintaining glucose metabolism. Because the expression levels of antioxidant enzymes are generally low in pancreatic $\beta$-cells, treatment of pancreatic $\beta$-cells with antioxidant enzymes and/or antioxidant reagents has been reported to rescue $\beta$-cells from oxidative damage in rodent diabetic models [45-47]. It is also known that various dietary conditions, such as methionine- and choline-deficient diets as well as high-fat diets, enhance oxidative stress in the liver and impair metabolic regulation of the tissue $[48,49]$. Therefore, the antioxidant function of the Keap1-Nrf2 system seems to play an important role in the maintenance of glucose metabolism through both insulin secretion and glucose utilization in insulin-sensitive tissues.

It has been reported that Nrf2 also regulates lipid metabolism-related genes [50]. ChIP-seq (chromatin immunoprecipitation sequencing) analyses revealed that the Nrf2-MafG heterodimer binds to a large number of metabolism-related genes [15]. Importantly, Nrf2 robustly regulates glucose metabolism-related genes and induces metabolic reprogramming from glycolysis to the pentose phosphate pathway in cancer cells [14]. The role that Nrf2 plays in the regulation of metabolism-related gene 
expression seems to be very important in maintaining glucose homeostasis in animals [51].

\section{Oxidative stress damages pancreatic $\beta$-cells}

Pancreatic $\beta$-cell failure is an important factor in the development and/or progression of type 2 diabetes (T2D), as loss of pancreatic $\beta$-cell mass and function seems to provoke hyperglycemia, which leads to the development of diabetes $[52,53]$. Indeed, oxidative stress is enhanced in pancreatic islets of rodent models of diabetes, $d b / d b$ mice and Goto-Kakizaki (GK) rats [54-57]. Consistent with these observations, immunohistological analyses of the oxidative DNA damage marker 8-OHdG (8-hydroxy-2'-deoxyguanosine) have revealed that oxidative stress is increased in pancreatic islets of T2D patients [58].

To overcome oxidative stress-mediated pancreatic $\beta$-cell damage, overexpression of antioxidant enzymes and antioxidant reagents has been tested in rodent models of diabetes. Pancreatic $\beta$-cell-specific overexpression of antioxidant genes, e.g., catalase, glutathione peroxidase $1(G p x l)$ and superoxide dismutase 1 (Sodl), ameliorates damage to the cells in rodent diabetic models [59-61]. Antioxidant reagents improve insulin secretion from pancreatic islets [62] and ameliorate pancreatic $\beta$-cell damage in rodent diabetic models [47]. These findings suggest that the enhancement of antioxidant enzymes may be a useful strategy for pancreatic $\beta$-cell protection. Although several chemicals are reported to suppress oxidative stress in pancreatic $\beta$-cells [63], they are still premature for use in drug development, and further searches for additional potent targets are needed to protect pancreatic $\beta$-cells in T2D patients. 


\section{The Keap1-Nrf2 system induces antioxidant enzymes in pancreatic $\beta$-cells}

Because the Keap1-Nrf2 system typically contributes to cytoprotection by inducing a set of antioxidant and drug-metabolizing enzyme genes, the roles that Nrf2 plays in pancreatic $\beta$-cells have been examined. Oral CDDO-Im administration to mice strongly stabilizes and accumulates $\mathrm{Nrf} 2$ in the nuclei of pancreatic $\beta$-cells [64]. CDDO-Im treatment also enhances the expression of Nrf2 target antioxidant enzyme genes in pancreatic islets [65]. These findings indicate that the Nrf2-inducing electrophile CDDO-Im activates the Keap1-Nrf2 pathway in pancreatic $\beta$-cells. In addition to CDDO-Im, the pancreatic $\beta$-cell-specific Keapl knockout genetically induces Nrf2 and also enhances Nrf2 target antioxidant enzyme gene expression in pancreatic islets [64]. In contrast, $N r f 2$ gene knockout decreases the expression of antioxidant enzyme genes in pancreatic islets $[64,65]$. These results indicate that the Keap1-Nrf2 system does function in pancreatic $\beta$-cells and that Nrf2 regulates antioxidant enzyme gene transcription in pancreatic $\beta$-cells.

\section{The Keap1-Nrf2 system contributes to pancreatic $\beta$-cell protection}

As Nrf2 intensively induces its target genes in pancreatic $\beta$-cells, the roles of the Keap1-Nrf2 system in antioxidant enzyme regulation for the protection of pancreatic $\beta$-cells against oxidative stress have been extensively examined (Fig. 2). To clarify the antioxidant functions of Nrf2 in pancreatic $\beta$-cells under ROS- and RNS-mediated stress conditions, transgenic mouse lines overexpressing inducible NO synthase (iNOS) 
specifically in pancreatic $\beta$-cells have been employed. Analyses of the iNOS transgenic mice clearly demonstrated that Nrf2 induction strongly suppresses ROS/RNS levels in pancreatic $\beta$-cells as well as ROS/RNS-mediated $\beta$-cell damage [64]. In addition to blocking ROS/RNS-mediated damage, Nrf2 also plays critical roles in pancreatic $\beta$-cell protection against arsenite-mediated damage [66]. These findings indicate that the Nrf2-mediated antioxidant response is crucial for pancreatic $\beta$-cell protection against ROS/RNS and xenobiotics.

In addition to these antioxidant functions, Nrf2 appears to prevent pancreatic $\beta$-cell damage through multiple other mechanisms. For instance, the Nrf2 inducer sulforaphane strongly suppresses cytokine-mediated iNOS and COX-2 (cylooxygenase 2) induction and thereby ameliorates pancreatic $\beta$-cell damage [67], indicating that Nrf2 contributes to the suppression of inflammation in pancreatic $\beta$-cells. Nrf2 also plays important roles in the maintenance of autophagy in pancreatic $\beta$-cells [68]. Nrf2 regulates the expression of proteasome catalytic subunits and contributes to the endoplasmic reticulum (ER) stress response in pancreatic $\beta$-cells [69]. Thus, Nrf2 modulates inflammation and major cellular protein degradation systems, i.e., proteasome and autophagy, in pancreatic $\beta$-cells. As shown in Figure 2, these wide-ranging observations demonstrate that the Keap1-Nrf2 system protects pancreatic $\beta$-cells against stress through multiple critical pathways.

Although the Keap1-Nrf2 system's role in the protection of pancreatic $\beta$-cells has been well characterized, the potential functions of this pathway in the regulation of other islet component cells have not been clarified yet, e.g., $\alpha$-cells, $\delta$-cells and PP-cells. It has been reported that pancreatic $\beta$-cells can dedifferentiate under stressed conditions 
and that they sometimes convert to the other cell types, such as $\alpha$-cells, $\delta$-cells or PP-cells, in type 2 diabetic model mouse islets [70]. In iNOS transgenic mice, the population of insulin-positive cells is decreased compared with that of insulin-negative cells in pancreatic islets [64]. An insulin promoter driven Cre recombinase reporter system has revealed that nitrosative stress in insulin-positive cells indeed promote conversion of the cells to insulin-negative/glucagon-positive cells in iNOS transgenic mouse pancreatic islets (our unpublished data). Nrf2 induction clearly increases the population of insulin-positive cells compared with that of insulin-negative cells in pancreatic islets of iNOS transgenic mice [64], suggesting that the Keap1-Nrf2 system likely prevents pancreatic $\beta$-cell dedifferentiation to the other insulin-negative cell types in pancreatic islets in the ROS/RNS-stressed condition.

\section{Oxidative stress and pancreatic $\beta$-cell functions}

The roles that oxidative stress plays in pancreatic $\beta$-cells are still enigmatic and remain to be clarified. It has been reported that in pancreatic $\beta$-cells, oxidative stress inhibits the respiratory chain and suppresses glucose metabolism-related enzyme activity, leading to reduction of ATP production and impairment of insulin release [71, 72]. In fact, glucose-stimulated insulin secretion (GSIS) is suppressed by high glucose-mediated oxidative stress [73]. Simultaneously, oxidative stress decreases insulin gene expression in pancreatic $\beta$-cells of $d b / d b$ mice by suppressing the level of MafA and PDX-1 transcription factors [47, 74]. These diverse findings indicate that oxidative stress impairs pancreatic $\beta$-cell function. 
In contrast, there is accumulating evidence suggesting that oxidative stress stimulates insulin release from pancreatic $\beta$-cells. For instance, hydrogen peroxide is reported to stimulate GSIS [75, 76]. Electrophilic stresses mediated by DEM and sulforaphane also facilitate insulin secretion from pancreatic $\beta$-cells $[75,77]$. By contrast, antioxidant reagents suppress GSIS [75, 78]. These findings indicate that oxidative and electrophilic stresses stimulate insulin secretion from pancreatic $\beta$-cell cells. While the mechanisms through which oxidative and electrophilic stresses increase insulin secretion are not fully understood, the possibility that ROS act as intracellular signals is intriguing in this context [79].

\section{Nrf2 induction model and insulin resistance}

The Nrf2 inducers CDDO-Im, CDDO-Me (CDDO methyl ester) and oltipraz have been suggested to improve systemic insulin resistance in murine diabetes and obesity models [65, 80-82]. Nrf2 inducers enhance the phosphorylation of AMP-activated protein kinase (AMPK) and increase glucose uptake while suppressing glucose production in liver $[80,81]$, indicating that chemical Nrf2 induction modulates AMPK signaling and improves insulin resistance. However, these pharmacological approaches retain limitations inherent to each drug and have never offered clear-cut resolution.

Therefore, genetic approaches have also been employed to evaluate the effects of persistent Nrf2 induction on glucose metabolism. Although Keap1 knockout $\left(\right.$ Keapl $\left.^{-/-}\right)$mice experience lethality at 3 weeks after birth, with hyperkeratosis in the esophagus and forestomach [83], this problem was overcome by utilizing a 
hypomorphic allele of Keapl (Keapl $\left.{ }^{f l o x}\right)$ [84]. Combinatorial use of the Keapl flox allele and the Keap1-null allele (Keap1 $1^{\text {floxflox }}$ or Keapl ${ }^{\text {flox/- }}$ ) provides a gradient of Keap1 expression, and these mouse lines are referred to as Keapl-knockdown (Keapl-KD) mice. Keap $1^{\text {floxflox }}$ and Keapl ${ }^{\text {flox/- }}$ mice escape lethality but show constitutive Nrf2 stabilization, and expression levels of Nrf2 target genes are increased in various tissues.

Genetic Nrf2 induction in Keap ${ }^{f l o x /-}$ mutant mice significantly suppresses the elevation of blood glucose levels in both $d b / d b$ and high calorie-diet-induced diabetic mice [65]. Using $d b / d b::$ Keapl $1^{\text {flox/- }}$ mice, it was demonstrated that Nrf2 suppresses the expression of the gluconeogenesis-related enzyme gene glucose 6-phosphatase (G6pc) in liver and abrogates gluconeogenesis in a pyruvate tolerance test [65]. Nrf2 also suppresses G6pc gene expression in murine cultured AML12 hepatocytes under cAMP analogue and CREB (cAMP response element binding protein) stimulation [65]. These results indicate that Nrf2 suppresses $G 6 p c$ expression levels through the repression of the cAMP-CREB signaling pathway in hepatocytes. In addition to the G6pc gene, Nrf2 also decreases the expression levels of other gluconeogenesis-related genes, including fructose-1,6-bisphosphatase 1 (Fbpl), peroxisome proliferator-activated receptor $\gamma$ coactivator $1 \alpha(P G C 1 \alpha$ or Ppargcla) and Nr4a2, in $d b / d b$ mouse liver [65]. In addition, genetic Nrf2 induction enhanced insulin sensitivity relative to control mice in an insulin tolerance test (ITT). In Keap floxflox $^{\text {IT }}$ mice, a milder genetic Nrf2 induction model than the Keapl $I^{\text {flox/- }}$ mice, Nrf2-mediated enhancement of AMPK phosphorylation [85] and lowering of blood glucose levels in a glucose tolerance test (GTT) were observed [85]. Thus, Nrf2 induction improves 
insulin resistance in mouse models of diabetes.

\section{Nrf2 induction and obesity}

As obesity is a critical factor for the progression of insulin resistance [86], control of obesity is an important issue for our understanding of the onset and/or progression of diabetes mellitus. In this regard, pharmacological Nrf2 induction by CDDO analogues, including CDDO-Im, CDDO-EA (CDDO-ethyl amide, RTA 405) and dihydro-CDDO-TFEA (dihydro-CDDO-trifluoroethyl amide, dh404), appeared to suppress body weight gain in rodent diabetic models $[87,88]$. Consistent with these observations, administration of CDDO-Me decreased body weight in diabetic nephropathy patients in human clinical studies $[89,90]$.

Genetic Nrf2 induction in Keap $1^{\text {flox/- }}$ mutant mice offers another important perspective in this context. Genetic Nrf2 induction suppressed body weight gain under high calorie-diet feeding conditions [65], increased skeletal muscle oxygen consumption and protected DIO model mice against hypokinesis [65]. Nrf2 induction also increased mitochondrial metabolism, oxygen consumption and glucose uptake [91, 92].

Fibroblast growth factor 21 (FGF21) is an important metabolic regulator that exerts anti-obesity effects [93]. An intriguing observation is that both chemical and genetic induction of Nrf2 elevate plasma FGF21 levels in murine diabetic models [94]. These findings suggest that activation of the Keap1-Nrf2 signaling pathway provokes anti-obesity effects and that this may be an additional benefit of the clinical use of this pathway. 


\section{Nrf2 depletion and insulin resistance}

Several reports have claimed that Nrf2 depletion suppresses insulin resistance and obesity. These reports are heavily dependent on analyses of Nrf2 knockout mice. For instance, it was reported that blood glucose levels of $N r f 2$ knockout mice are lower than those of wild-type mice $[49,65,95,96]$; that, Nrf2 depletion decreases fat pad and body weight $[95,97]$; and that insulin signaling is enhanced in Nrf2 knockout mouse liver and skeletal muscle [49]. While both genetic and pharmacological Nrf2 induction enhance plasma FGF21 levels [94], this factor was also elevated in Nrf2 knockout mice under long-term high fat-diet feeding conditions [98].

In contrast to the above observations, Nrf2 depletion is reported to increase blood glucose levels; in $L e p^{o b / o b}$ and Nrf2 compound knockout mice $\left(N r 2^{-/}:: L e p^{o b / o b}\right)$, glucose intolerance is worsened compared with $L e p^{o b / o b}$ mice. Lep ${ }^{o b / o b}$ mice with either global $N r f 2$ knockout or fat tissue-specific $N r f 2$ knockout also show increased blood glucose levels, indicating that Nrf2 contributes to the suppression of glucose intolerance in adipose tissues [99]. In addition to modulating Lep $^{o b / o b}$ fat tissue, Nrf2 knockout further impairs insulin signaling in primary hepatocytes [100]. These observations suggest that Nrf2 potentially exerts protective effects for insulin signaling under metabolically stressed conditions.

These two lines of evidence appear contradictory, and further studies are mandatory to clarify the situation. In this regard, it is interesting to note that gain-of-Nrf2 function studies using both genetic (Keap1 knockdown) and pharmacological approaches (see above) support the contention that Nrf2 acts to suppress blood glucose 
levels, consistent with the latter observations. We surmise that multiple approaches are essential to elucidate the full array of Nrf2 functions, as $\mathrm{Nrf} 2$ has pleiotropic activities, and a single type of approach may reveal only one aspect of the full picture.

\section{Diabetic complications and the Keap1-Nrf2 system}

As hyperglycemia induces the formation of glycation products as well as oxidative stress, it is known that oxidative stress contributes to the pathogenesis of diabetic complications $[11,12,101]$. Nrf2 depletion increases renal oxidative and nitrosative stress in the streptozotocin (STZ)-induced mouse diabetes model [102]. Pathological analyses revealed that administration of Nrf2 inducers, i.e., sulforaphane and cinnamic aldehyde, suppressed STZ-mediated diabetic nephropathy [103]. Administration of CDDO-Me increased the glomerular filtration rate in diabetic nephropathy patients [89, 90]; in contrast, $N r f 2$ depletion abrogates the temporal increment of creatinine clearance after diabetes onset in mice [102]. These findings indicate that Nrf2 pathologically and functionally protects the kidney against diabetic damage.

Nrf2 also helps to prevent diabetic retinopathy and cardiomyopathy. In the STZ-induced diabetic model, dysfunction of the blood-retina barrier and neuronal function are worsened in $N r f 2$ knockout mice compared with wild-type mice, suggesting that the Keap1-Nrf2 system helps to protect against the onset and/or progression of diabetic retinopathy [104]. In addition, the Nrf2 inducer dihydro-CDDO-TFEA suppressed diabetes-mediated cardiac nitrosative damage [105]. Taken together, these wide-ranging data demonstrate that the Keap1-Nrf2 system 
intimately protects tissues against diabetes-mediated damage and that Nrf2 induction suppresses oxidative damage-mediated diabetic complications.

\section{CNC family transcription factors in glucose metabolism}

The CNC family transcription factors Nrf1 and Nrf3 (NF-E2-related factor 1 and 3) also heterodimerize with sMaf and exert transcriptional functions thorough ARE/EpREs [106, 107]. The liver-specific Nrfl knockout model exhibits fatty liver, and metabolome and gene expression analyses clarified that Nrf1 is heavily involved in the regulation of amino acid and lipid metabolism [108]. It has been reported that Nrf1 negatively regulates metabolism-related genes, including cystine transporter and lipid metabolism genes [109]. Intriguingly, overexpression of Nrf1 induces insulin resistance and the onset of diabetes mellitus in DIO model mice, the mirror image of the effects of Nrf2 [110].

Genome-wide association studies have also revealed that Nrf3 is related to the waist-hip ratio [111], indicating that $\mathrm{Nrf3}$ contributes to fat distribution and the pathogenesis of obesity. Hence, members of the CNC family of transcription factors, especially $\mathrm{Nrf1}$, Nrf2 and $\mathrm{Nrf3}$, are involved in the onset and/or progression of metabolic disorders, though their contributions are distinct.

\section{Conclusions}

Accumulating lines of evidence have revealed that activation of the Keap1-Nrf2 system contributes to the suppression of diabetes mellitus. One important finding is that Nrf2 induction protects pancreatic $\beta$-cells against diverse types of damage, 
including that related to oxidants, toxic chemicals, and inflammation (Fig. 2). The other important result is that the activation of Nrf2 signaling suppresses the onset and/or progression of insulin resistance (Fig. 3) by enhancing AMPK phosphorylation, oxygen consumption and glucose uptake and, suppressing gluconeogenesis and body weight gain. These functions of Nrf2 together lead to the protection of the body against diabetes.

Nrf2 activation has also emerged as a hopeful target for the prevention of diabetic complications. For instance, administration of the Nrf2 inducer CDDO-Me increased the glomerular filtration rate in diabetic nephropathy patients [89]. Although the BEACON study employing stage 4 diabetic nephropathy patients was unfortunately discontinued due to an increase in cardiovascular events [90], a series of studies, including the BEAM study [89], clearly provide a concrete proof-of-concept that Nrf2 inducers act to prevent the progression of diabetic nephropathy. Nrf2 inducers may be applicable for slightly earlier stages of diabetic nephropathy than those used in the BEACON study. Concomitantly, investigations into the cause of the cardiovascular events associated with CDDO-Me will be beneficial Nrf2 inducers in advanced diabetic nephropathy.

In summary, the Keap1-Nrf2 system plays important roles in the maintenance of glucose homeostasis and in the suppression of the onset and/or progression of diabetes mellitus. The significance of Nrf2 is now increasing as a therapeutic target for the regulation of blood glucose levels and diabetic complications is steadily increasing. 


\section{Acknowledgments}

This work was supported by the Grants-in-Aids for Scientific Research on Innovative Areas and Scientific Research from the Ministry of Education, Science, Sports and Culture (MEXT) (M.Y.), the Create Revolutionary Technological Seeds for Science and Technology Innovation program (CREST) of the Japanese Technology Agency (JST) (M.Y.), Grants-in-Aids for Scientific Research from the Japan Society for the Promotion of Science (JSPS) (Grant Numbers 24249015 (M.Y.), 90396474 (A.U.) and 26893008 (Y.Y.)), the Takeda Foundation (M.Y.), the Naito Foundation (M.Y.) and the Japanese Foundation for Applied Enzymology (A.U.). 


\section{References}

[1] K. Itoh, K. Igarashi, N. Hayashi, M. Nishizawa, M. Yamamoto, Mol Cell Biol 15 (1995) 4184-4193.

[2]

G.P. Sykiotis, D. Bohmann, Sci Signal 3 (2010) re3.

[3] K. Itoh, T. Chiba, S. Takahashi, T. Ishii, K. Igarashi, Y. Katoh, T. Oyake, N. Hayashi, K. Satoh, I. Hatayama, M. Yamamoto, Y. Nabeshima, Biochem Biophys Res Commun 236 (1997) 313-322.

[4] T. Ishii, K. Itoh, S. Takahashi, H. Sato, T. Yanagawa, Y. Katoh, S. Bannai, M. Yamamoto, J Biol Chem 275 (2000) 16023-16029.

[5] K. Itoh, N. Wakabayashi, Y. Katoh, T. Ishii, K. Igarashi, J.D. Engel, M. Yamamoto, Genes Dev 13 (1999) 76-86.

[6] E.W. Gregg, Y. Li, J. Wang, N.R. Burrows, M.K. Ali, D. Rolka, D.E. Williams, L. Geiss, N Engl J Med 370 (2014) 1514-1523.

[7] S. Lenzen, J. Drinkgern, M. Tiedge, Free Radic Biol Med 20 (1996) 463-466.

[8] K. Grankvist, S.L. Marklund, I.B. Täljedal, Biochem J 199 (1981) 393-398.

[9] A. Ceriello, Diabetes Care 26 (2003) 1589-1596.

[10] T. Nishikawa, D. Edelstein, X.L. Du, S. Yamagishi, T. Matsumura, Y. Kaneda, M.A. Yorek, D. Beebe, P.J. Oates, H.P. Hammes, I. Giardino, M. Brownlee, Nature 404 (2000) 787-790.

[11] M.J. Sheetz, G.L. King, JAMA 288 (2002) 2579-2588.

[12] M. Brownlee, Nature 414 (2001) 813-820.

[13] P. Dandona, K. Thusu, S. Cook, B. Snyder, J. Makowski, D. Armstrong, T. Nicotera, Lancet 347 (1996) 444-445.

[14] Y. Mitsuishi, K. Taguchi, Y. Kawatani, T. Shibata, T. Nukiwa, H. Aburatani, M. Yamamoto, H. Motohashi, Cancer Cell 22 (2012) 66-79.

[15] Y. Hirotsu, F. Katsuoka, R. Funayama, T. Nagashima, Y. Nishida, K.

Nakayama, J.D. Engel, M. Yamamoto, Nucleic Acids Res 40 (2012) 10228-10239.

[16] K. Igarashi, K. Kataoka, K. Itoh, N. Hayashi, M. Nishizawa, M. Yamamoto, Nature 367 (1994) 568-572.

[17] H. Motohashi, F. Katsuoka, J.D. Engel, M. Yamamoto, Proc Natl Acad Sci U S A 101 (2004) 6379-6384.

[18] F. Katsuoka, H. Motohashi, T. Ishii, H. Aburatani, J.D. Engel, M. Yamamoto, 
Mol Cell Biol 25 (2005) 8044-8051.

[19] H. Yamazaki, F. Katsuoka, H. Motohashi, J.D. Engel, M. Yamamoto, Mol Cell Biol 32 (2012) 808-816.

[20] T.H. Rushmore, M.R. Morton, C.B. Pickett, J Biol Chem 266 (1991) 11632-11639.

[21] R.S. Friling, A. Bensimon, Y. Tichauer, V. Daniel, Proc Natl Acad Sci U S A 87 (1990) 6258-6262.

[22] A. Enomoto, K. Itoh, E. Nagayoshi, J. Haruta, T. Kimura, T. O'Connor, T. Harada, M. Yamamoto, Toxicol Sci 59 (2001) 169-177.

[23] M.K. Kwak, P.A. Egner, P.M. Dolan, M. Ramos-Gomez, J.D. Groopman, K. Itoh, M. Yamamoto, T.W. Kensler, Mutat Res 480-481 (2001) 305-315.

[24] H. Sasaki, H. Sato, K. Kuriyama-Matsumura, K. Sato, K. Maebara, H. Wang, M. Tamba, K. Itoh, M. Yamamoto, S. Bannai, J Biol Chem 277 (2002) 44765-44771.

[25] A. Hayashi, H. Suzuki, K. Itoh, M. Yamamoto, Y. Sugiyama, Biochem Biophys Res Commun 310 (2003) 824-829.

[26] J. Alam, D. Stewart, C. Touchard, S. Boinapally, A.M. Choi, J.L. Cook, J Biol Chem 274 (1999) 26071-26078.

[27] H.Y. Cho, A.E. Jedlicka, S.P. Reddy, T.W. Kensler, M. Yamamoto, L.Y. Zhang, S.R. Kleeberger, Am J Respir Cell Mol Biol 26 (2002) 175-182.

[28] R.K. Thimmulappa, K.H. Mai, S. Srisuma, T.W. Kensler, M. Yamamoto, S. Biswal, Cancer Res 62 (2002) 5196-5203.

[29] A. Sakurai, M. Nishimoto, S. Himeno, N. Imura, M. Tsujimoto, M. Kunimoto, S. Hara, J Cell Physiol 203 (2005) 529-537.

[30] F.X. Soriano, F. Léveillé, S. Papadia, L.G. Higgins, J. Varley, P. Baxter, J.D. Hayes, G.E. Hardingham, J Neurochem 107 (2008) 533-543.

[31] H.Y. Cho, S.P. Reddy, M. Yamamoto, S.R. Kleeberger, FASEB J 18 (2004) 1258-1260.

[32] Y. Katoh, K. Itoh, E. Yoshida, M. Miyagishi, A. Fukamizu, M. Yamamoto, Genes Cells 6 (2001) 857-868.

[33] P. Rada, A.I. Rojo, S. Chowdhry, M. McMahon, J.D. Hayes, A. Cuadrado, Mol Cell Biol 31 (2011) 1121-1133.

[34] S. Chowdhry, Y. Zhang, M. McMahon, C. Sutherland, A. Cuadrado, J.D. Hayes, Oncogene 32 (2013) 3765-3781. 
Cell Biol 26 (2006) 2887-2900.

[36] B. Padmanabhan, K.I. Tong, T. Ohta, Y. Nakamura, M. Scharlock, M. Ohtsuji, M.I. Kang, A. Kobayashi, S. Yokoyama, M. Yamamoto, Mol Cell 21 (2006) 689-700.

[37] T. Fukutomi, K. Takagi, T. Mizushima, N. Ohuchi, M. Yamamoto, Mol Cell Biol 34 (2014) 832-846.

[38] W. Chen, Z. Sun, X.J. Wang, T. Jiang, Z. Huang, D. Fang, D.D. Zhang, Mol Cell 34 (2009) 663-673.

[39] K.I. Tong, B. Padmanabhan, A. Kobayashi, C. Shang, Y. Hirotsu, S.

Yokoyama, M. Yamamoto, Mol Cell Biol 27 (2007) 7511-7521.

[40] A. Kobayashi, M.I. Kang, H. Okawa, M. Ohtsuji, Y. Zenke, T. Chiba, K. Igarashi, M. Yamamoto, Mol Cell Biol 24 (2004) 7130-7139.

[41] A. Uruno, H. Motohashi, Nitric Oxide 25 (2011) 153-160.

[42] K. Takaya, T. Suzuki, H. Motohashi, K. Onodera, S. Satomi, T.W. Kensler, M. Yamamoto, Free Radic Biol Med 53 (2012) 817-827.

[43] M. Kobayashi, L. Li, N. Iwamoto, Y. Nakajima-Takagi, H. Kaneko, Y.

Nakayama, M. Eguchi, Y. Wada, Y. Kumagai, M. Yamamoto, Mol Cell Biol 29 (2009) 493-502.

[44] S. Fujii, T. Sawa, H. Ihara, K.I. Tong, T. Ida, T. Okamoto, A.K. Ahtesham, Y. Ishima, H. Motohashi, M. Yamamoto, T. Akaike, J Biol Chem 285 (2010) 23970-23984. [45] K. Grankvist, S. Marklund, J. Sehlin, I.B. Täljedal, Biochem J 182 (1979) $17-25$.

[46] K. Grankvist, S. Marklund, I.B. Täljedal, Nature 294 (1981) 158-160.

[47] H. Kaneto, Y. Kajimoto, J. Miyagawa, T. Matsuoka, Y. Fujitani, Y. Umayahara, T. Hanafusa, Y. Matsuzawa, Y. Yamasaki, M. Hori, Diabetes 48 (1999) 2398-2406.

[48] H. Sugimoto, K. Okada, J. Shoda, E. Warabi, K. Ishige, T. Ueda, K. Taguchi, T. Yanagawa, A. Nakahara, I. Hyodo, T. Ishii, M. Yamamoto, Am J Physiol Gastrointest Liver Physiol 298 (2010) G283-294.

[49] P.J. Meakin, S. Chowdhry, R.S. Sharma, F.B. Ashford, S.V. Walsh, R.J.

McCrimmon, A.T. Dinkova-Kostova, J.F. Dillon, J.D. Hayes, M.L. Ashford, Mol Cell Biol (2014).

[50] J.D. Hayes, A.T. Dinkova-Kostova, Trends Biochem Sci 39 (2014) 199-218.

[51] D.V. Chartoumpekis, T.W. Kensler, Curr Diabetes Rev 9 (2013) 137-145. 
[52] A. Vetere, A. Choudhary, S.M. Burns, B.K. Wagner, Nat Rev Drug Discov 13 (2014) 278-289.

[53] E. Bonora, Nutr Metab Cardiovasc Dis 18 (2008) 74-83.

[54] Y.E. Lee, J.W. Kim, E.M. Lee, Y.B. Ahn, K.H. Song, K.H. Yoon, H.W. Kim, C.W. Park, G. Li, Z. Liu, S.H. Ko, PLoS One 7 (2012) e50412.

[55] S. Fujimoto, E. Mukai, N. Inagaki, Prog Biophys Mol Biol 107 (2011) 304-310.

[56] Y. Ihara, S. Toyokuni, K. Uchida, H. Odaka, T. Tanaka, H. Ikeda, H. Hiai, Y. Seino, Y. Yamada, Diabetes 48 (1999) 927-932.

[57] B. Portha, M.H. Giroix, C. Tourrel-Cuzin, H. Le-Stunff, J. Movassat, Methods Mol Biol 933 (2012) 125-159.

[58] H. Sakuraba, H. Mizukami, N. Yagihashi, R. Wada, C. Hanyu, S. Yagihashi, Diabetologia 45 (2002) 85-96.

[59] B. Xu, J.T. Moritz, P.N. Epstein, Free Radic Biol Med 27 (1999) 830-837.

[60] J.S. Harmon, M. Bogdani, S.D. Parazzoli, S.S. Mak, E.A. Oseid, M.

Berghmans, R.C. Leboeuf, R.P. Robertson, Endocrinology 150 (2009) 4855-4862.

[61] H.M. Kubisch, J. Wang, T.M. Bray, J.P. Phillips, Diabetes 46 (1997) 1563-1566.

[62] M. Sasaki, S. Fujimoto, Y. Sato, Y. Nishi, E. Mukai, G. Yamano, H. Sato, Y. Tahara, K. Ogura, K. Nagashima, N. Inagaki, Diabetes 62 (2013) 1996-2003.

[63] E. Mukai, S. Fujimoto, H. Sato, C. Oneyama, R. Kominato, Y. Sato, M. Sasaki, Y. Nishi, M. Okada, N. Inagaki, Diabetes 60 (2011) 218-226.

[64] Y. Yagishita, T. Fukutomi, A. Sugawara, H. Kawamura, T. Takahashi, J. Pi, A. Uruno, M. Yamamoto, Diabetes 63 (2014) 605-618.

[65] A. Uruno, Y. Furusawa, Y. Yagishita, T. Fukutomi, H. Muramatsu, T. Negishi, A. Sugawara, T.W. Kensler, M. Yamamoto, Mol Cell Biol 33 (2013) 2996-3010.

[66] B. Yang, J. Fu, H. Zheng, P. Xue, K. Yarborough, C.G. Woods, Y. Hou, Q. Zhang, M.E. Andersen, J. Pi, Toxicol Appl Pharmacol 264 (2012) 315-323.

[67] M.Y. Song, E.K. Kim, W.S. Moon, J.W. Park, H.J. Kim, H.S. So, R. Park, K.B. Kwon, B.H. Park, Toxicol Appl Pharmacol 235 (2009) 57-67.

[68] W. Li, W. Wu, H. Song, F. Wang, H. Li, L. Chen, Y. Lai, J.S. Janicki, K.W. Ward, C.J. Meyer, X.L. Wang, D. Tang, T. Cui, FEBS Lett 588 (2014) 2115-2124.

[69] S. Lee, E.G. Hur, I.G. Ryoo, K.A. Jung, J. Kwak, M.K. Kwak, Toxicol Appl 
Pharmacol 264 (2012) 431-438.

[70] C. Talchai, S. Xuan, H.V. Lin, L. Sussel, D. Accili, Cell 150 (2012) 1223-1234.

[71] E. Rebelato, F. Abdulkader, R. Curi, A.R. Carpinelli, Metabolism 59 (2010) 409-413.

[72] E. Rebelato, F. Abdulkader, R. Curi, A.R. Carpinelli, PLoS One 6 (2011) e24507.

[73] K. Sakai, K. Matsumoto, T. Nishikawa, M. Suefuji, K. Nakamaru, Y.

Hirashima, J. Kawashima, T. Shirotani, K. Ichinose, M. Brownlee, E. Araki, Biochem Biophys Res Commun 300 (2003) 216-222.

[74] J.S. Harmon, R. Stein, R.P. Robertson, J Biol Chem 280 (2005) 11107-11113.

[75] J. Pi, Y. Bai, Q. Zhang, V. Wong, L.M. Floering, K. Daniel, J.M. Reece, J.T.

Deeney, M.E. Andersen, B.E. Corkey, S. Collins, Diabetes 56 (2007) 1783-1791.

[76] M. Saadeh, T.C. Ferrante, A. Kane, O. Shirihai, B.E. Corkey, J.T. Deeney, PLoS One 7 (2012) e30200.

[77] J. Fu, Q. Zhang, C.G. Woods, H. Zheng, B. Yang, W. Qu, M.E. Andersen, J. Pi, Pharm Res 30 (2013) 2248-2259.

[78] C. Leloup, C. Tourrel-Cuzin, C. Magnan, M. Karaca, J. Castel, L. Carneiro, A.L. Colombani, A. Ktorza, L. Casteilla, L. Pénicaud, Diabetes 58 (2009) 673-681.

[79] S.G. Rhee, Science 312 (2006) 1882-1883.

[80] P.K. Saha, V.T. Reddy, M. Konopleva, M. Andreeff, L. Chan, J Biol Chem 285 (2010) 40581-40592.

[81] E.J. Bae, Y.M. Yang, J.W. Kim, S.G. Kim, Hepatology 46 (2007) 730-739.

[82] Z. Yu, W. Shao, Y. Chiang, W. Foltz, Z. Zhang, W. Ling, I.G. Fantus, T. Jin, Diabetologia 54 (2011) 922-934.

[83] N. Wakabayashi, K. Itoh, J. Wakabayashi, H. Motohashi, S. Noda, S.

Takahashi, S. Imakado, T. Kotsuji, F. Otsuka, D.R. Roop, T. Harada, J.D. Engel, M. Yamamoto, Nat Genet 35 (2003) 238-245.

[84] K. Taguchi, J.M. Maher, T. Suzuki, Y. Kawatani, H. Motohashi, M. Yamamoto, Mol Cell Biol 30 (2010) 3016-3026.

[85] J. Xu, A.C. Donepudi, J.E. Moscovitz, A.L. Slitt, PLoS One 8 (2013) e79841.

[86] S.E. Kahn, R.L. Hull, K.M. Utzschneider, Nature 444 (2006) 840-846.

[87] S. Shin, J. Wakabayashi, M.S. Yates, N. Wakabayashi, P.M. Dolan, S. Aja, K.T. 
Liby, M.B. Sporn, M. Yamamoto, T.W. Kensler, Eur J Pharmacol 620 (2009) 138-144.

[88] M. Chin, C.Y. Lee, J.C. Chuang, R. Bumeister, W.C. Wigley, S.T. Sonis, K.W. Ward, C. Meyer, Am J Physiol Renal Physiol 304 (2013) F1438-1446.

[89] P.E. Pergola, P. Raskin, R.D. Toto, C.J. Meyer, J.W. Huff, E.B. Grossman, M. Krauth, S. Ruiz, P. Audhya, H. Christ-Schmidt, J. Wittes, D.G. Warnock, B.S. Investigators, N Engl J Med 365 (2011) 327-336.

[90] D. de Zeeuw, T. Akizawa, P. Audhya, G.L. Bakris, M. Chin, H.

Christ-Schmidt, A. Goldsberry, M. Houser, M. Krauth, H.J. Lambers Heerspink, J.J. McMurray, C.J. Meyer, H.H. Parving, G. Remuzzi, R.D. Toto, N.D. Vaziri, C. Wanner, J. Wittes, D. Wrolstad, G.M. Chertow, B.T. Investigators, N Engl J Med 369 (2013) 2492-2503.

[91] K.M. Holmström, L. Baird, Y. Zhang, I. Hargreaves, A. Chalasani, J.M. Land, L. Stanyer, M. Yamamoto, A.T. Dinkova-Kostova, A.Y. Abramov, Biol Open 2 (2013) 761-770.

[92] E.H. Heiss, D. Schachner, K. Zimmermann, V.M. Dirsch, Redox Biol 1 (2013) 359-365.

[93] J. Xu, D.J. Lloyd, C. Hale, S. Stanislaus, M. Chen, G. Sivits, S. Vonderfecht, R. Hecht, Y.S. Li, R.A. Lindberg, J.L. Chen, D.Y. Jung, Z. Zhang, H.J. Ko, J.K. Kim, M.M. Véniant, Diabetes 58 (2009) 250-259.

[94] Y. Furusawa, A. Uruno, Y. Yagishita, C. Higashi, M. Yamamoto, Genes Cells (2014).

[95] A.K. Meher, P.R. Sharma, V.A. Lira, M. Yamamoto, T.W. Kensler, Z. Yan, N. Leitinger, Free Radic Biol Med 52 (2012) 1708-1715.

[96] Y.K. Zhang, K.C. Wu, J. Liu, C.D. Klaassen, Toxicol Appl Pharmacol 264 (2012) 305-314.

[97] J. Pi, L. Leung, P. Xue, W. Wang, Y. Hou, D. Liu, E. Yehuda-Shnaidman, C. Lee, J. Lau, T.W. Kurtz, J.Y. Chan, J Biol Chem 285 (2010) 9292-9300.

[98] D.V. Chartoumpekis, P.G. Ziros, A.I. Psyrogiannis, A.G. Papavassiliou, V.E. Kyriazopoulou, G.P. Sykiotis, I.G. Habeos, Diabetes 60 (2011) 2465-2473.

[99] P. Xue, Y. Hou, Y. Chen, B. Yang, J. Fu, H. Zheng, K. Yarborough, C.G. Woods, D. Liu, M. Yamamoto, Q. Zhang, M.E. Andersen, J. Pi, Diabetes 62 (2013) 845-854.

[100] T.A. Beyer, W. Xu, D. Teupser, U. auf dem Keller, P. Bugnon, E. Hildt, J. 
Thiery, Y.W. Kan, S. Werner, EMBO J 27 (2008) 212-223.

[101] N.B. Ruderman, J.R. Williamson, M. Brownlee, FASEB J 6 (1992) 2905-2914.

[102] K. Yoh, A. Hirayama, K. Ishizaki, A. Yamada, M. Takeuchi, S. Yamagishi, N. Morito, T. Nakano, M. Ojima, H. Shimohata, K. Itoh, S. Takahashi, M. Yamamoto, Genes Cells 13 (2008) 1159-1170.

[103] H. Zheng, S.A. Whitman, W. Wu, G.T. Wondrak, P.K. Wong, D. Fang, D.D. Zhang, Diabetes 60 (2011) 3055-3066.

[104] Z. Xu, Y. Wei, J. Gong, H. Cho, J.K. Park, E.R. Sung, H. Huang, L. Wu, C. Eberhart, J.T. Handa, Y. Du, T.S. Kern, R. Thimmulappa, A.J. Barber, S. Biswal, E.J. Duh, Diabetologia 57 (2014) 204-213.

[105] Y. Tan, T. Ichikawa, J. Li, Q. Si, H. Yang, X. Chen, C.S. Goldblatt, C.J. Meyer, X. Li, L. Cai, T. Cui, Diabetes 60 (2011) 625-633.

[106] M. Ohtsuji, F. Katsuoka, A. Kobayashi, H. Aburatani, J.D. Hayes, M. Yamamoto, J Biol Chem 283 (2008) 33554-33562.

[107] A. Kobayashi, E. Ito, T. Toki, K. Kogame, S. Takahashi, K. Igarashi, N. Hayashi, M. Yamamoto, J Biol Chem 274 (1999) 6443-6452.

[108] Y. Hirotsu, N. Hataya, F. Katsuoka, M. Yamamoto, Mol Cell Biol 32 (2012) 2760-2770.

[109] T. Tsujita, V. Peirce, L. Baird, Y. Matsuyama, M. Takaku, S.V. Walsh, J.L. Griffin, A. Uruno, M. Yamamoto, J.D. Hayes, Mol Cell Biol 34 (2014) 3800-3816.

[110] Y. Hirotsu, C. Higashi, T. Fukutomi, F. Katsuoka, T. Tsujita, Y. Yagishita, Y. Matsuyama, H. Motohashi, A. Uruno, M. Yamamoto, Genes Cells 19 (2014) 650-665.

[111] I.M. Heid, A.U. Jackson, J.C. Randall, T.W. Winkler, L. Qi, V. Steinthorsdottir, G. Thorleifsson, M.C. Zillikens, E.K. Speliotes, R. Mägi, T. Workalemahu, C.C. White, N. Bouatia-Naji, T.B. Harris, S.I. Berndt, E. Ingelsson, C.J. Willer, M.N. Weedon, J. Luan, S. Vedantam, T. Esko, T.O. Kilpeläinen, Z. Kutalik, S. Li, K.L. Monda, A.L. Dixon, C.C. Holmes, L.M. Kaplan, L. Liang, J.L. Min, M.F. Moffatt, C. Molony, G. Nicholson, E.E. Schadt, K.T. Zondervan, M.F. Feitosa, T. Ferreira, H. Lango Allen, R.J. Weyant, E. Wheeler, A.R. Wood, K. Estrada, M.E. Goddard, G. Lettre, M. Mangino, D.R. Nyholt, S. Purcell, A.V. Smith, P.M. Visscher, J. Yang, S.A. McCarroll, J. Nemesh, B.F. Voight, D. Absher, N. Amin, T. Aspelund, L. Coin, N.L. Glazer, C. Hayward, N.L. Heard-Costa, J.J. Hottenga, A. Johansson, T. Johnson, M. Kaakinen, K. Kapur, S. 
Ketkar, J.W. Knowles, P. Kraft, A.T. Kraja, C. Lamina, M.F. Leitzmann, B. McKnight, A.P. Morris, K.K. Ong, J.R. Perry, M.J. Peters, O. Polasek, I. Prokopenko, N.W. Rayner, S. Ripatti, F. Rivadeneira, N.R. Robertson, S. Sanna, U. Sovio, I. Surakka, A. Teumer, S. van Wingerden, V. Vitart, J.H. Zhao, C. Cavalcanti-Proença, P.S. Chines, E. Fisher, J.R. Kulzer, C. Lecoeur, N. Narisu, C. Sandholt, L.J. Scott, K. Silander, K. Stark, M.L. Tammesoo, T.M. Teslovich, N.J. Timpson, R.M. Watanabe, R. Welch, D.I. Chasman, M.N. Cooper, J.O. Jansson, J. Kettunen, R.W. Lawrence, N. Pellikka, M. Perola, L. Vandenput, H. Alavere, P. Almgren, L.D. Atwood, A.J. Bennett, R. Biffar, L.L. Bonnycastle, S.R. Bornstein, T.A. Buchanan, H. Campbell, I.N. Day, M. Dei, M. Dörr, P. Elliott, M.R. Erdos, J.G. Eriksson, N.B. Freimer, M. Fu, S. Gaget, E.J. Geus, A.P. Gjesing, H. Grallert, J. Grässler, C.J. Groves, C. Guiducci, A.L. Hartikainen, N. Hassanali, A.S. Havulinna, K.H. Herzig, A.A. Hicks, J. Hui, W. Igl, P. Jousilahti, A. Jula, E. Kajantie, L. Kinnunen, I. Kolcic, S. Koskinen, P. Kovacs, H.K. Kroemer, V. Krzelj, J. Kuusisto, K. Kvaloy, J. Laitinen, O. Lantieri, G.M. Lathrop, M.L. Lokki, R.N. Luben, B. Ludwig, W.L. McArdle, A. McCarthy, M.A. Morken, M. Nelis, M.J. Neville, G. Paré, A.N. Parker, J.F. Peden, I. Pichler, K.H. Pietiläinen, C.G. Platou, A. Pouta, M. Ridderstråle, N.J. Samani, J. Saramies, J. Sinisalo, J.H. Smit, R.J. Strawbridge, H.M. Stringham, A.J. Swift, M. Teder-Laving, B. Thomson, G. Usala, J.B. van Meurs, G.J. van Ommen, V. Vatin, C.B. Volpato, H. Wallaschofski, G.B. Walters, E. Widen, S.H. Wild, G. Willemsen, D.R. Witte, L. Zgaga, P. Zitting, J.P. Beilby, A.L. James, M. Kähönen, T. Lehtimäki, M.S. Nieminen, C. Ohlsson, L.J. Palmer, O. Raitakari, P.M. Ridker, M. Stumvoll, A. Tönjes, J. Viikari, B. Balkau, Y. Ben-Shlomo, R.N. Bergman, H. Boeing, G.D. Smith, S. Ebrahim, P. Froguel, T. Hansen, C. Hengstenberg, K. Hveem, B. Isomaa, T. Jørgensen, F. Karpe, K.T. Khaw, M. Laakso, D.A. Lawlor, M. Marre, T. Meitinger, A. Metspalu, K. Midthjell, O. Pedersen, V. Salomaa, P.E. Schwarz, T. Tuomi, J. Tuomilehto, T.T. Valle, N.J. Wareham, A.M. Arnold, J.S. Beckmann, S. Bergmann, E. Boerwinkle, D.I. Boomsma, M.J. Caulfield, F.S. Collins, G. Eiriksdottir, V. Gudnason, U. Gyllensten, A. Hamsten, A.T. Hattersley, A. Hofman, F.B. Hu, T. Illig, C. Iribarren, M.R. Jarvelin, W.H. Kao, J. Kaprio, L.J. Launer, P.B. Munroe, B. Oostra, B.W. Penninx, P.P. Pramstaller, B.M. Psaty, T. Quertermous, A. Rissanen, I. Rudan, A.R. Shuldiner, N. Soranzo, T.D. Spector, A.C. Syvanen, M. Uda, A. Uitterlinden, H. Völzke, P. Vollenweider, J.F. Wilson, J.C. Witteman, A.F. Wright, G.R. Abecasis, M. Boehnke, I.B. Borecki, P. Deloukas, T.M. Frayling, L.C. Groop, T. Haritunians, D.J. Hunter, R.C. 
Kaplan, K.E. North, J.R. O'Connell, L. Peltonen, D. Schlessinger, D.P. Strachan, J.N. Hirschhorn, T.L. Assimes, H.E. Wichmann, U. Thorsteinsdottir, C.M. van Duijn, K.

Stefansson, L.A. Cupples, R.J. Loos, I. Barroso, M.I. McCarthy, C.S. Fox, K.L. Mohlke, C.M. Lindgren, MAGIC, Nat Genet 42 (2010) 949-960. 


\section{Figure legends}

Fig. 1. Structure and interaction of Nrf2 and Keap1. (a) Nrf2 contains six well-conserved Neh (Human NRF2-chicken $\underline{E} C H$ homology) domains, from Neh1 to Neh6. The Neh2 domain is involved in the binding to Keap1. The Neh4 and Neh5 domains interact with CBP (CREB-binding protein) and exert transactivation activity. Neh6 acts as a Keap1-independent degron by interacting with $\beta$-TrCP $(\beta$-transducin repeat-containing protein). Neh1 dimerizes with sMaf (small Maf) proteins and binds DNA. (b) Interaction between Keap1 and Nrf2 under unstressed and stressed conditions. The DLGex and ETGE motifs in the Neh2 domain of Nrf2 bind to the Keap1 homodimer under unstressed conditions in the cytosol, leading to Nrf2 degradation through the proteasome pathway. In the presence of oxidative and/or electrophilic stress, DLGex is dissociated from Keap1, and Nrf2 escapes from

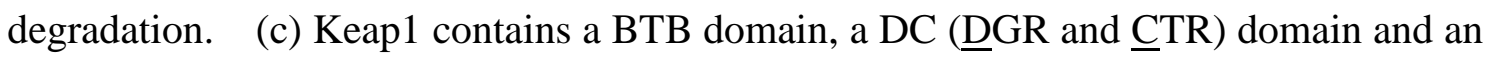
IVR domain. The BTB domain modulates Keap1 homodimerization, and the DC domain contributes to the interaction with Nrf2. C151, C273 and C288 are representative highly reactive cysteine residues.

Fig. 2. Pancreatic $\beta$-cell protection by the Keap1-Nrf2 system. Stress-mediated Keap1 modifications stabilize Nrf2, allowing $\mathrm{Nrf} 2$ to accumulate in the nucleus and heterodimerize with sMaf proteins. The Nrf2-sMaf heterodimer binds to cis-acting ARE/EpRE motifs and induces target gene expression. Nrf2 increases the expression of antioxidant and detoxification enzymes and decreases ROS levels in pancreatic 
$\beta$-cells. Nrf2 also suppresses inflammation-related gene expression, including iNOS and COX-2. Nrf2 contributes to the maintenance of proteolytic systems, including proteasome and autophagy. As a result, the Keap1-Nrf2 system protects pancreatic $\beta$-cells against various stresses.

Fig. 3. Nrf2 induction prevents diabetes mellitus through the improvement of insulin resistance and the protection of pancreatic $\beta$-cells. The Keap1-Nrf2 system modulates gluconeogenesis, glucose uptake and oxygen consumption. Nrf2 is also involved in the activation of AMPK, and Nrf2 induction exerts anti-obesity effects. Nrf2 protects pancreatic $\beta$-cells through multiple functions. 
Figure 1 Uruno et al.

(a)

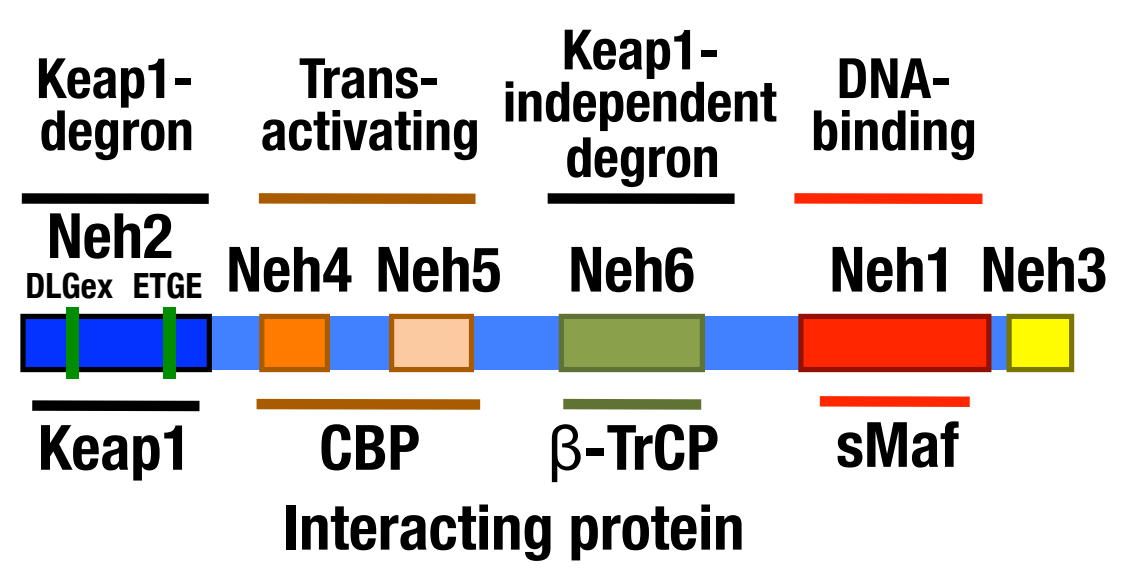

(b) Unstressed conditions

Stressed conditions

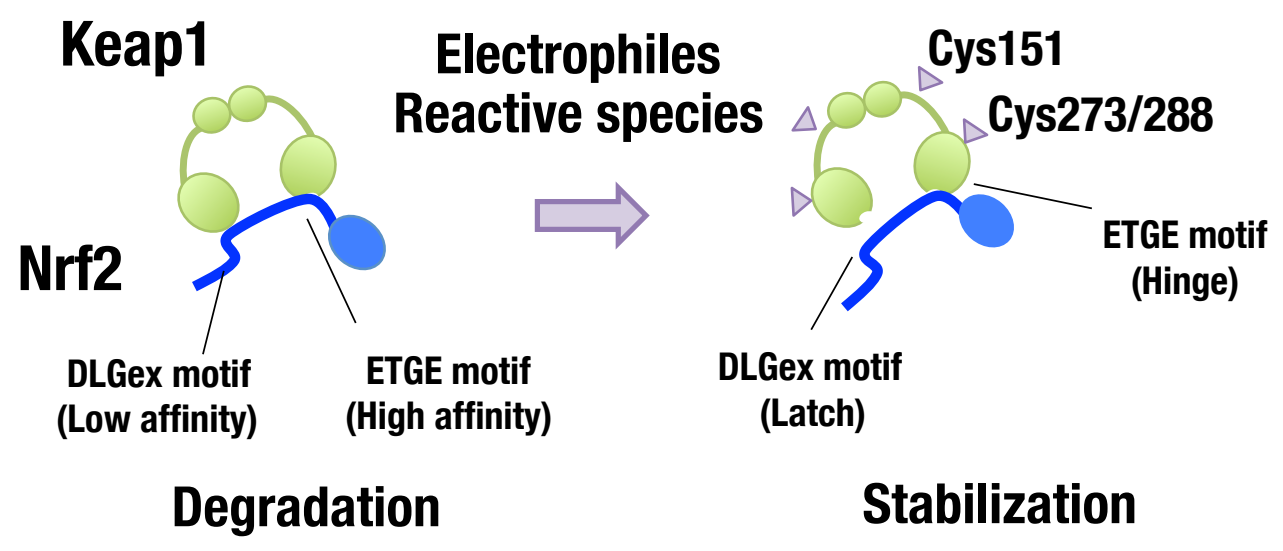

(c)

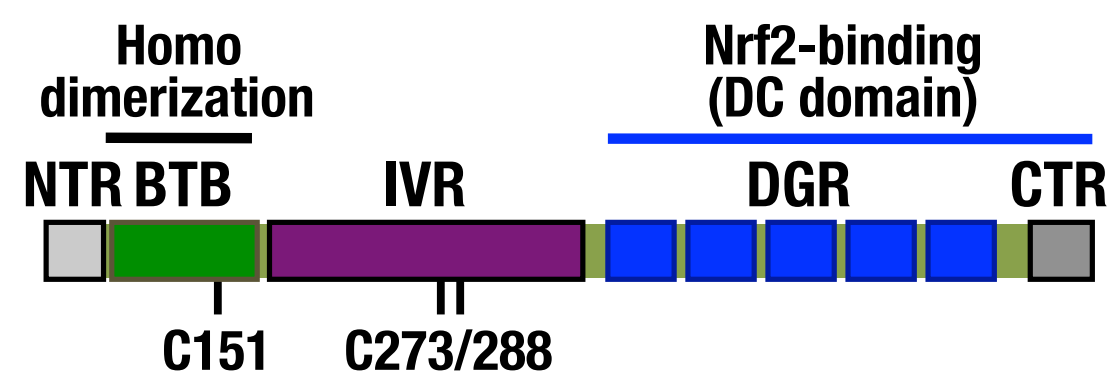


Figure 2 Uruno et al.

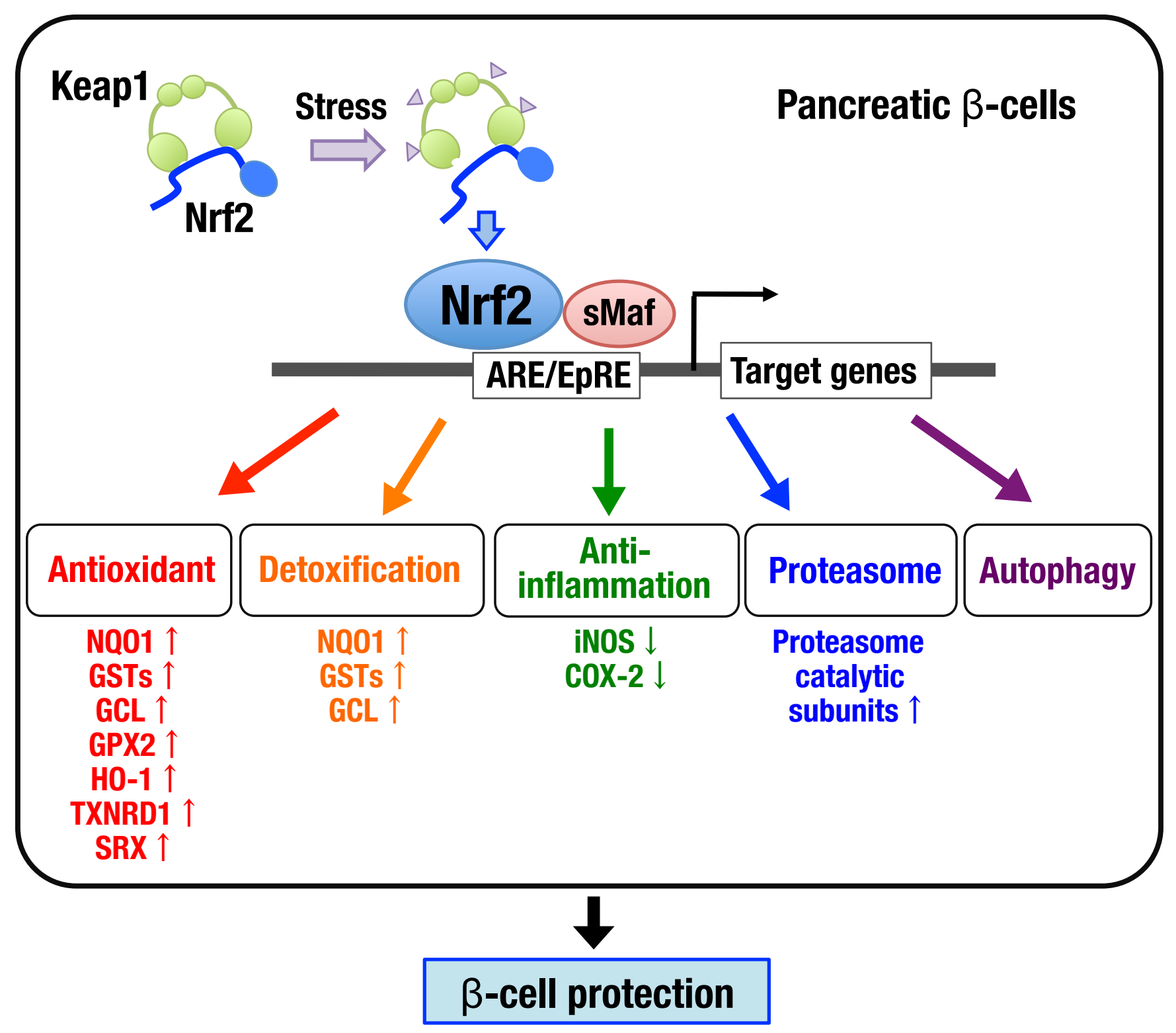


Figure 3 Uruno et al.

\section{Nrf2 induction}

Liver Skeletal muscle Adipose tissues

Pancreatic $\beta$-cells

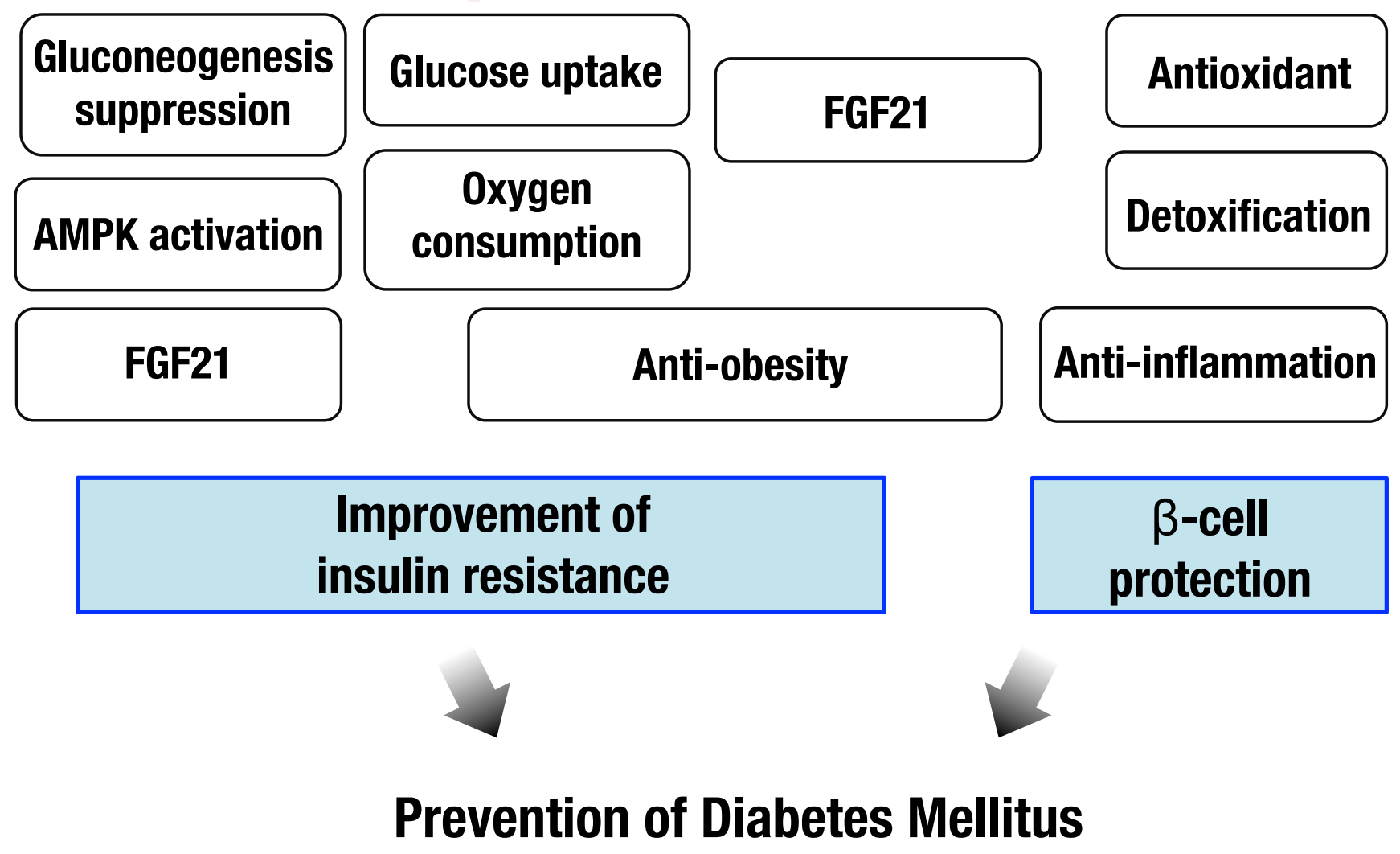

